\title{
EFFECT OF CINNAMON OIL AND SCORPION VENOM ON ORAL SQUAMOUS CELL CARCINOMA CELL LINE (IN VITRO STUDY)
}

\author{
Seham Ahmed Abdel Ghani* and Basma Abdelrahman Ahmed*
}

\begin{abstract}
Review: Oral squamous cell carcinoma (OSCC), one of the most common neoplasms in the head and neck, is a major public health challenge. Cinnamon oils have proved to have powerful anticancer properties. Scorpion Venoms are rich in active sources which are used for treatment of multiple diseases including cancer. There is no evidence about the effect and the type of pharmacological interaction in combined treatment of this cinnamon oil with scorpion venom against cancer cells.
\end{abstract}

Aim of study: The current study aimed to unveil the cytotoxic effect and apoptotic potential of cinnamon oil, scorpion venom and their combination on OSCC cell line.

Material and Methods: OSCC cell line was used in this study. The study design was divided into four groups. Group I (control), group II (cinnamon oil treated), group III (scorpion venom treated) and group IV (cinnamon oil + scorpion venom treated). Cytotoxcity was examined using MTT assay while apoptosis was detected by calculating nuclear area factor (NAF) and BAX gene expression of different groups.

Results: The combination group showed the lowest IC50 of all groups. It also revealed the lowest mean NAF and the highest mean fold change in BAX gene expression

Conclusion: Combination of Cinnamon oil and Scorpion venom could be a promising anticancer cure for OSCC as this combination showed an effective cytotoxic and pro-apoptotic effects on OSCC cell line.

KEY WARDS, OSCC, Cinnamon, scorpion venom, apoptosis, BAX gene.

\section{INTRODUCTION}

Oral squamous cell carcinoma (OSCC), the sixth most common neoplasm in head and neck region, is a major health challenge due to high morbidity and mortality rates. The disease has multifactorial etiology, however, tobacco and alcohol consumption accounts for $40 \%$ of the malignancies and $60 \%$ of deaths ${ }^{[1]}$. The mechanism of carcinogenesis is a complex one that involves; sustaining uncontrolled cell proliferation, evading immunity and hindering apoptosis. The role of infectious organisms like

\footnotetext{
* Lecturer of Oral Pathology, Faculty of Dentistry, Ain Shams University
} 
Streptococcus mutans and Candida albicans in yielding cancer should not be underestimated. Hence, the ideal cancer therapy is not only a one targeting malignant cells, but also targeting the causative carcinogenic organisms ${ }^{[2-3]}$.

Combination therapies of surgery, chemotherapy and radiotherapy are the standard treatment for the disease yet. Unfortunately, these procedures are associated with a number of side effects including esthetic and functional impairment ${ }^{[4]}$. Herbal therapy is being encouraged recently by researchers as an anticancer adjuvant treatment. This could be attributed to the anti-oxidant and antimicrobial activities of the polyphenols, flavanoids, alkaloids and other constituents of herbs ${ }^{[5]}$.

Cinnamon is a spice of the Lauraceae family. It is widely used in cooking and perfume industry. Oil extracts differ from variable parts of the plant. Oil from bark is Cinnamonaldehyde, eugenol is the leaf oil whereas the root oil is camphor. Cinnamon oils are powerful antimicrobial agents and strong immunity boosters ${ }^{[5,6]}$.

Cinnamaldehyde and Eugenol are reported to have an anti-inflammatory and neuroprotective effects. They decrease the production of inflammatory mediators, cytokines, and reactive oxygen species in diseases like Alzheimer's disease and gut injuries ${ }^{[7,8]}$. In a recent preclinical study, it was documented that cinnamaldehyde has an antioxidant, anti-proliferative and pro-apoptotic properties that reduced visfatin-induced breast cancer progression ${ }^{[9]}$.

Venoms are rich in pharmacologically active molecules which are used as a cure of numerous diseases including cancer. The venom proteins revealed anti-proliferative, cytotoxic, pro-apoptotic, and immuno- suppressive effects on cancer cell lines ${ }^{[10]}$. Scorpion venom is a complex mixture of toxins, enzymes and antimicrobial peptides. It was proved that scorpion venom has anticarcinogenic action through binding specifically to cell membranes thus affecting cell proliferation and migration ${ }^{[11]}$.
Moreover, it exerts an apoptotic activity by induction of caspase-dependent apoptotic pathways or cell cycle arrest in various cell lines as breast and colon cancer cell lines ${ }^{[12]}$.

Apoptosis is a highly programmed mechanism by which cells die. The intrinsic pathway of apoptosis is regulated by pro-apoptotic and anti-apoptotic genes. BAX gene is a pro-apoptotic gene, which is targeted by cancer therapy in an attempt to kill cancer cells

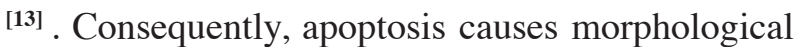
changes of cells and nuclei. Nuclear area factor (NAF) is considered a method for measuring these morphological changes as it determines changes in nuclear surface area and circularity ${ }^{[14]}$.

There is no evidence about the effect and the type of pharmacological interaction in combined treatment of this scorpion venom with chemotherapeutic drugs or herbs against oral cancer and normal oral cells. Accordingly, the aim of the present study was to examine and compare the cytotoxic effects and apoptotic potentials of cinnamon oil and scorpion venom on OSCC cell line, also to evaluate the combined effect of both on OSCC cell line.

\section{MATERIALS AND METHODS}

\section{The material used in this study}

- Cell line: SCC25 cell line of the American Type Culture Collection (ATCC) was obtained from NAWAH scientific, Cairo, Egypt. The cells were grown in Dulbeco's Modified Eagle's Medium (DMEM) (Sigma-Aldrich) at $\mathrm{PH}=7.2$ and $10 \%$ fetal bovine serum (FBS) (Sigma-Aldrich) at $37^{\circ} \mathrm{c}$.

- Scorpion venom: Leiurusquinquestriatus scorpion venom was a gift from Dr. Ali Fahmy at Scientific and Biotechnology Research Center-Al Azhar University.

- Cinnamon Oil 100\% natural pure bark oil (Cinnamaldehyde) was purchased from MAKIN-Pharmaceuticals Egypt. 


\section{METHODS}

\section{MTT assay for Determination of IC-50}

- The half maximal inhibitory concentration (IC50) of scorpion venom and cinnamon oil was obtained using (3-(4,5-dimethylthiazol-2-yl)2,5-diphenyltetrazolium bromide) tetrazolium reduction (MTT) assay, briefly the cells were seeded in 96-well plate in a volume of $100 \mu 1$ complete growth medium and placed in $\mathrm{CO} 2$ incubator at $37^{\circ} \mathrm{C}$ for $24 \mathrm{hrs}$. Each test included a blank well containing complete medium without cells. Serial concentrations, of 100,10 , $1,0.1$ and $0.01 \mu \mathrm{g} / \mathrm{ml}$ of each drug, were added individually and in combination. The plate was incubated at $37^{\circ} \mathrm{C}$ for 24 and $48 \mathrm{~h}$.

- MTT reagent was added to the wells and the cultures were returned to the incubator for $12 \mathrm{~h}$. After the incubation period, cultures were removed from the incubator and the resulting purple formazan crystals were dissolved by MTT solubilization solution. The optical density (OD) of each well was spectrophotometrically measured at a wave length of $570 \mathrm{~nm}$ with an ELISA microplate reader (BIOLINE ELIZA READER). The IC50 for 24 and $48 \mathrm{~h}$ were calculated using Excel.

\section{Hematoxylin and Eosin (H and E) Staining}

Cells were seeded in 6 well plate for $24 \mathrm{~h}$ then the IC50 doses at $48 \mathrm{~h}$ of venom, cinnamon oil, a combination of both were applied to the cells. After $48 \mathrm{~h}$ the cells were trypsinized, centrifuged and a pellet was formed. Cells from each group were applied on a glass slide, fixed with methanol $10 \%$ and stained with $\mathrm{H}$ and $\mathrm{E}$. The slides were then examined by a light microscope (BX60, Olympus, Japan) and 10 photos of each group were captured by digital camera (C5060, Olympus, Japan) mounted on the microscope.

\section{Measurement of Nuclear Area Factor (NAF)}

Images were transferred to the computer system for analysis. The circularity and surface area of nuclei of cells in each image were measured using Image J, 1.41a, (NIH, USA) image analysis software. This was performed in the Precision Measurement Unit, Oral Pathology Department, Faculty of Dentistry, Ain Shams University. The NAF was calculated as circularity multiplied by surface area. The mean NAF of cells in each slide was then obtained.

\section{Quantitative Real Time Polymerase Chain Reac- tion (qRT-PCR) of BAX Gene Expression}

QRT-PCR was performed to measure the quantity of BAX RNA. Genomic RNA was isolated from cells of each group using (Qiagen RNA extraction kit). The extracted RNA was stored at -80c. BAX and $\beta$-actin RNA was amplified separately by incubating on a Step One (Applied Biosystem). The reaction mixture $(25 \mu \mathrm{L})$ contained $100 \mathrm{ng}$ of genomic RNA, $0.25 \mu \mathrm{mol} / \mathrm{L}$ of the primer, and SYBR green reagent supermix (Bio-Rad laboratories, Hercules, CA). All PCR reactions were performed in sets of triplets. The primer sequence for the studied target gene (BAX) and reference housekeeping gene ( $\beta$-actin) was as follows:

BAX F: 5'-ATG GAC GGG TCC GGG GAG-3' BAX R: 5'-ATC CAG CCC AAC AGC CGC-3' $\beta$-actin F:5'-ATC GTG GGG CGC CCC AGG CAC-3'

After the qRT-PCR run the data were expressed in cycle threshold $(\mathrm{Ct})$. The PCR data sheet includes $\mathrm{Ct}$ values of assessed gene (BAX) and the house keeping gene ( $\beta$-actin). The relative quantitation (RQ) of each target gene is quantified according to the calculation of delta-delta $\mathrm{Ct}(\Delta \Delta \mathrm{Ct})$. We calculated the RQ of each gene by taking $2-\Delta \Delta \mathrm{Ct}$ as following:

$\beta$-actin R:5'-CTC CTT AAT GTC ACG CAC GAT TTC-3' 
$\Delta \Delta C t=[(C t$ target, sample $)-(C t$ ref, sample $)]-$ [(Ct target, control)-(Ct ref, control)]

Where: $\mathrm{Ct}$ target, control $=\mathrm{Ct}$ value of gene of interest in control DNA

$\mathrm{Ct}$ ref, control $=\mathrm{Ct}$ value of reference gene in control DNA

$\mathrm{Ct}$ target, sample $=\mathrm{Ct}$ value of gene of interest in tested sample

$\mathrm{Ct}$ ref, sample $=\mathrm{Ct}$ value of reference gene in tested sample

\section{Statistical Analysis}

Data were coded and entered using the statistical package for the Social Sciences (SPSS) version 26 (IBM Corp., Armonk, NY, USA). Data were summarized using mean, standard deviation and standard error of the mean. Comparisons between groups were done using analysis of variance (ANOVA) with multiple comparisons post hoc Tukey test ${ }^{[15]}$, P-values less than 0.05 were considered as statistically significant.

\section{RESULTS}

\section{IC50 Results}

The detected IC50s for cinnamon oil were 90.40 and 42.95, scorpion venom were 37.20 and 8.27,

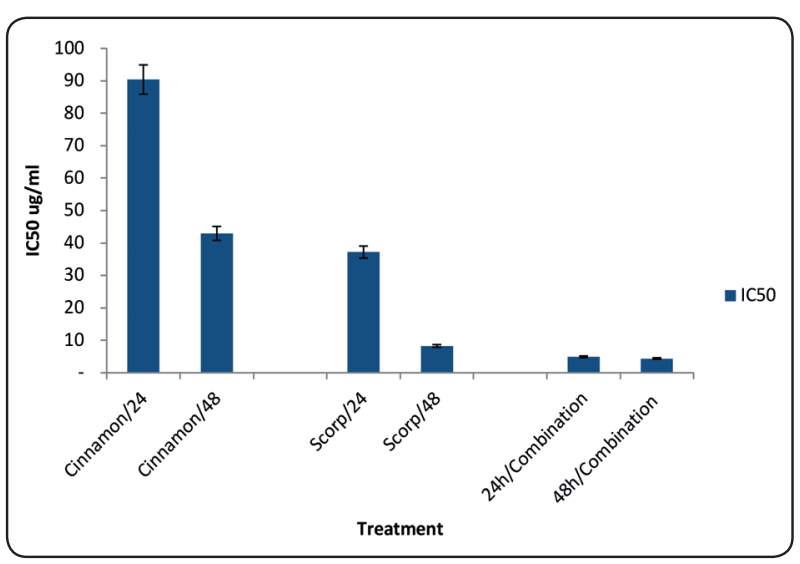

Fig. (1) A bar chart of the measured IC50 of scorpion venom, cinnamon oil and combination at 24 and $48 \mathrm{~h}$. while that of the combination were 4.93 and 4.40 for 24 and 48 h respectively (Fig.1)

\section{Hematoxylin and Eosin Results}

Cells of the control group revealed signs of dysplasia of cellular and nuclear pleomorphism and hyperchromatic nuclei (Fig. 2 a). Early apoptotic features of cellular and nuclear shrinkage, peripheral condensation of chromatin, nuclear and cellular membrane irregularities and cell membrane blebbing were observed in cinnamon, venom and combination groups (Fig 2 b, c, ,d,e,f,g). Apoptotic bodies which characterize late apoptosis were detected in cinnamon and combination groups (Fig. $2 \mathrm{c}, 2 \mathrm{~g}$ ) whereas, necrotic cells were noticed in venom and combination groups (Fig.2e, 2f)

\section{Statistical Results:}

\section{A) Nuclear Area Factor results}

Regarding mean NAF, a statistically significant difference between all groups could be detected ( $\mathrm{P}$ value $<0.001)$. There was a statistically significant reduction in mean NAF in the treated groups compared to the control group. The combination group revealed the least mean NAF value (8576.16) with no statistically significant difference between all treated groups (Table 1).

\section{B) BAX gene expression results}

The mean BAX gene expression statistically significantly changed between different groups ( $\mathrm{P}$ value $<0.001)$. A statistically significant increase in the mean gene expression between the control group and all the treatment groups could be observed. The combination group showed the highest mean value (9.35) while the oil group showed the least mean value (6.14) with statistically significant difference between the three treatment groups (Table 1). 


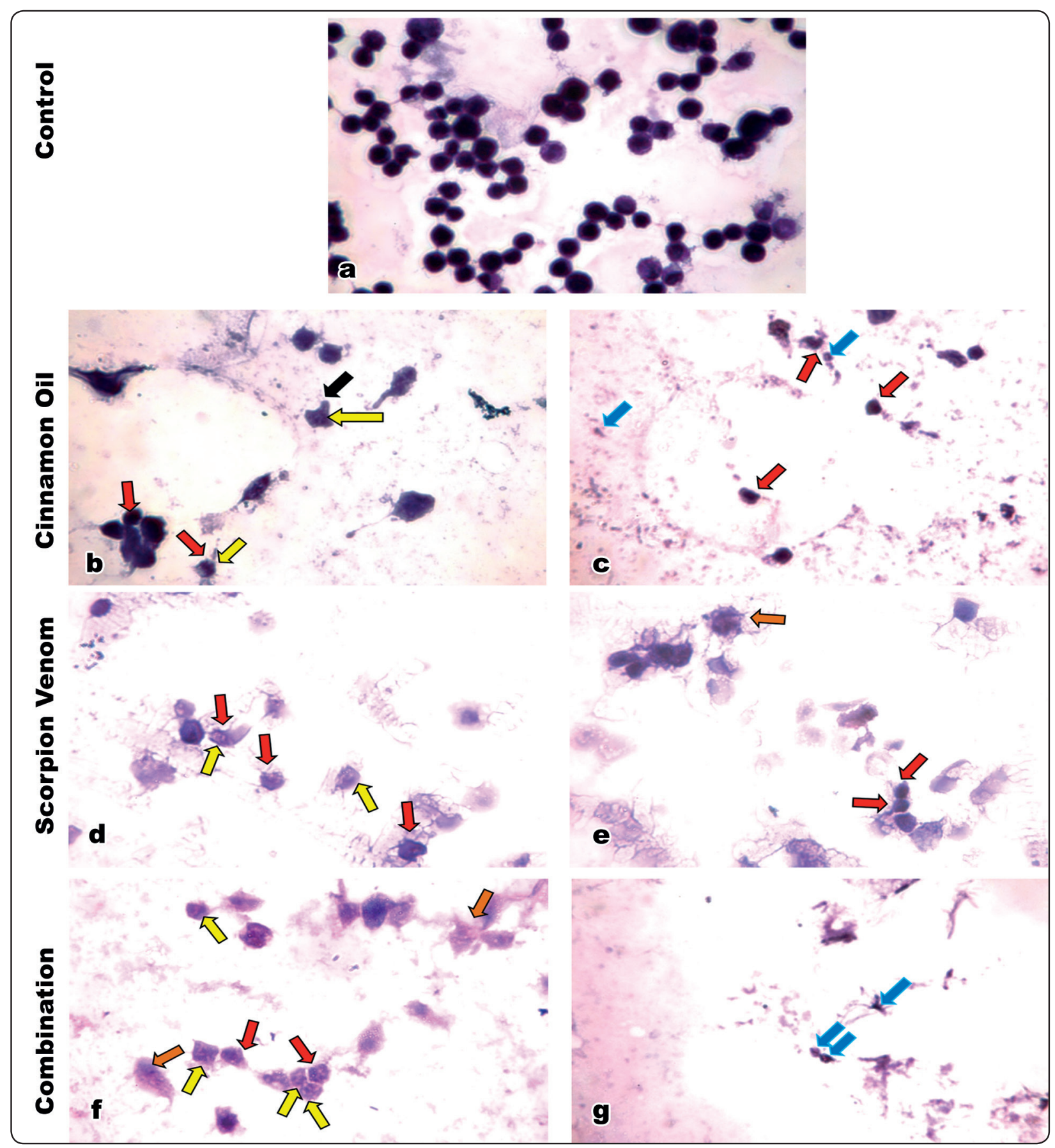

Fig. (2): A photomicrograph showing a: control group, b,c: cinnamon oil group, d,e: scorpion venom group, f, g: combination group. In all groups the red arrows show apoptotic cells with cellular and nuclear shrinkage, yellow arrows show peripheral condensation of chromatin, black arrow reveal cell membrane blebbing, blue arrows point to the apoptotic bodies and orange arrows reveal the necrotic cells (H and E, Original magnification $100 \mathrm{X}$, Oil). 
TABLE (1): Means, SD, SEM, values with different superscript letters denote a statistically significant difference, values $\leq 0.05$ were considered statistically significant.

\begin{tabular}{|c|c|c|c|c|c|c|}
\hline & & Control & Oil & Venom & Combination & $P$ value \\
\hline \multirow{3}{*}{$\begin{array}{l}\text { Nuclear area factor } \\
\text { (NAF) after } 48 \mathrm{~h}\end{array}$} & Mean & $33427.18^{b}$ & $10803.72^{\mathrm{a}}$ & $8892.60^{\mathrm{a}}$ & $8576.16^{\mathrm{a}}$ & \multirow{3}{*}{$<0.001$} \\
\hline & SD & 3230.24 & 3056.64 & 4768.77 & 3145.46 & \\
\hline & SEM & 1076.75 & 1018.88 & 1589.59 & 1048.49 & \\
\hline \multirow{3}{*}{$\begin{array}{l}\text { PCR of BAX Gene } \\
\text { Expression after } 48 \mathrm{~h}\end{array}$} & Mean & $1.00^{\mathrm{a}}$ & $6.14^{\mathrm{b}}$ & $7.31^{\mathrm{c}}$ & $9.35^{\mathrm{d}}$ & \multirow{3}{*}{$<0.001$} \\
\hline & SD & 0.00 & 0.18 & 0.39 & 0.47 & \\
\hline & SEM & 0.00 & 0.10 & 0.23 & 0.27 & \\
\hline
\end{tabular}

\section{DISCUSSION}

Oral squamous cell carcinoma is a type of cancer with high morbidity and mortality rates. It has a higher range of occurrence in developing countries. Herbs are rich sources of phytochemicals with variable anticancer and chemopreventive effects due to their antioxidant and antimicrobial properties [16]. In the present study, cinnamon oil was chosen due to the easy availability, and the use of this herb is well documented. Scorpion venom was used in our study as a biological anticancer agent that was previously proved to affect epithelial cancer cells like breast cancer cell lines with no obvious cytotoxic effect on normal cells ${ }^{[17,18]}$.

Combination therapies have evolved in attempt to increase the efficacy and reduce the side effects of chemo and radiotherapies in addition to surgical intervention ${ }^{[19]}$. In our study, we evaluated and compared the cytotoxic effect of cinnamon oil, scorpion venom and their combinations on OSCC cell line by using state of the art techniques; MTT assay and RT-PCR. Concerning RT-PCR, its increased sensitivity and specificity renders it a favorable option for quantitative analysis of cancer markers even with low copy targets ${ }^{[20]}$.

Moreover, the parameters used for nuclear morphometry in this study were thought to be useful to detect the apoptotic changes. The calculation of what is called NAF seemed to be a sensitive indicator for apoptotic changes. It could precisely measure the changes in surface area and circularity automatically by the software ${ }^{[14]}$.

In this study, an in vitro anticancer efficacy of cinnamon oil and scorpion venom against OSCC cell line was determined. The IC50 concentration exhibited by cinnamon oil extract was $90.40 \mu \mathrm{g} /$ $\mathrm{mL}, 42.95 \mu \mathrm{g} / \mathrm{mL} / 24 \mathrm{~h}, 48 \mathrm{~h}$ respectively, this is in accordance with previous studies which reported that the cinnamon oil Cinnamaldehyde exhibited cytotoxic effects on OSCC ${ }^{[21]}$ and breast cancer MDA-MB-231 [22]. It significantly inhibited proliferation, migration and invasion ability of cancer cells ${ }^{[21,22]}$.

In addition, the venom had a promising cytotoxic effect against OSCC cell line with IC50 37.20 and $8.27 / 24 \mathrm{~h}, 48 \mathrm{~h}$ respectively. This goes in accordance with Ding et al., 2014 who found that scorpion venom molecules revealed a potent cytotoxic action $^{[23]}$. Also, Zargan et al., 2011 reported that Androctonuscrassicauda scorpion venom inhibited the growth of human adenocarcinoma cell line (MCF-7) by exposure to different concentrations of the venom $(10,25,50,100$, and $200 \mathrm{mg} / \mathrm{mL})$ due to arresting S-phase of the cell cycle ${ }^{[24]}$. 
Results of the present study revealed a potential cytotoxic effect of combined use of cinnamon oil with scorpion venom than the use of single agent with IC50 $=4.93 \mu \mathrm{g} / \mathrm{mL}, 4.40 \mu \mathrm{g} / \mathrm{mL} / 24 \mathrm{~h}, 48 \mathrm{~h}$ respectively. This may be attributed to the fact that the combination of natural products potentiates the cytotoxic effect of individual product. This is consistent with another study conducted by Nazhvani et al., 2020 on OSCC cell line. They found that the combination of four herbal natural products had more effect than the combinations of two or three products, which by their turn had more effect than each one, individually. Interestingly, they also revealed that the combinations contained cinnamon had the highest effect in comparison to other studied combinations ${ }^{[25]}$.

In the present study, the data recorded from nuclear morphometric analysis revealed a statistically significant reduction in mean NAF in the treated groups compared to the control group. Early apoptotic features were observed in cinnamon, venom and combination treated groups. These data suggested that calculation of the NAF for cells in culture appears to be a useful morphological indicator of the early apoptotic process. This could be attributed to the proapototic effect of all treatment groups.

In agreement with our results, Herdwiani 2016 reported that cinnamon acts as an anti-cancer agent against various types of cancer cells such as basal cell carcinoma, breast cancer cell line (MCF7), epidermoid carcinoma (A431), and human OSCC (Ca9-22 and SCC12) ${ }^{[26]}$. The anti-cancer effect of cinnamon extract was directly related to the augmentation of apoptosis and inhibition of NFKB and AP1 activity ${ }^{[27]}$. Another in vitro study detected early and late stages of apoptosis or necrosis in the adenocarcinoma cell lines (MDA-MB-231) and early apoptotic stage in MCF-7 cells using Annexin V/PI staining ${ }^{[28]}$.
Moreover our results goes in accordance with, Al-Asmari et al., 2018 who revealed that scorpion venom-induced apoptosis in MDA- MB-231 cells when morphologically observed through fluorescent staining DAPI. The scorpion venom-treated group showed shrunken and marginated nuclei in cancer cells in contrast to large nucleus in the untreated cells ${ }^{[12]}$. Another study by Panja et al., 2021 used BmKn-2, a scorpion venom peptide, at $30 \mu \mathrm{g} / \mathrm{mL}$ to treat canine mammary gland tumors (CMGT) cell line. They found many apoptotic cells and few necrotic cells in CMGT treated cells; these results suggested that scorpion venom induced apoptotic cell death and created less inflammatory response ${ }^{[29]}$.

The combination group in the present study revealed the least NAF value in all treated groups, with no statistically significant difference between all treated groups. Apoptotic bodies which characterize late apoptosis were detected in cinnamon and combination groups whereas; necrotic cells were noticed in venom and combination groups.

In addition, we observed a statistically significant increase in the mean BAX gene expression between the control group and all the treatment groups. The combination group showed the highest mean value (9.35) while the oil group showed the least mean value (6.14) with statistically significant difference between the three treatment groups. This goes in accordance with $\mathrm{Li}$ et al. 2016 who detected a significant effect of Cinnamaldehyde in increasing Bax gene expression and inducing apoptosis in human colorectal cancer cells ${ }^{[30]}$.

Moreover, venoms and their toxins are known to induce cell cycle arrest at early stages in the G1, $\mathrm{G} 2$, and $\mathrm{S}$ phases, thereby avoiding the uncontrolled proliferation of cancer cells and inducing apoptotic cell death ${ }^{[12,24]}$. In his study Diaz- Garcia et al., 2013 also found that Rhopalurusjunceus overexpressed Bax, caspase 3, and caspase 9 in Hela cervical cancer cell lines ${ }^{[18]}$. BmKn-2 peptide 
and Rhopalurus junceus also were found to upregulate the pro-apoptotic genes p53 and Bax and down- regulate the anti-apoptotic gene $\mathrm{Bcl}-2$ in oral cancer ${ }^{[31]}$ and triple negative breast cancer ${ }^{[32]}$, respectively.

The mechanism of action of the combination of cinnamon oil with scorpion venom could be possibly due to the effect of both compounds on mitochondrial pathway of apoptosis which was examined here by their effect on BAX gene expression.

\section{CONCLUSION}

The present study clearly demonstrated high success rate of cinnamon oil and scorpion venom as an efficient anticancer agents on OSCC cells. The present data highlights the pro-apoptotic potential of cinnamon oil and scorpion venoms. Moreover, this study suggests the possibility of using the combined agents as apotential novel complementary or alternative therapies for OSCC.

\section{REFERENCES}

1. Prasad LK.: Burden of oral cancer:an Indian scenario.J Orofac Sci.2014;6(2):77.

2. MohdBakri M., MohdHussaini H. and RachelHolmes A.: Revisiting the association between candidal infection and carcinoma, particularly oral squamous cellcarcinoma.J Oral Microbiol.2010;2(1)10.

3. ValkoM., RhodesCJ. And MoncolJ.: Free radicals, metals and antioxidants in oxidative stress-induced cancer. Chem Biol Interact. 2006; 160(1):1-40.

4. Shukla S. and Shukla S.: Oral cancer-curse, cure and challenge. Indian J Surg. 2012;74(6):437-439.

5. Mohammadi M., Mirabzadeh, S., Shahvalizadeh R. and Hamishehkar H.: Development of novel active packaging films based on whey protein isolate incorporated with chitosan nanofiber and nano-formulated cinnamon oil. Int. J. Biol. Macromol. 2020; 149: 11-20.

6. Wariyapperuma W., Kannangara S. and Yasanandana S.: In vitro anti-diabetic effects and phytochemical profiling of novel varieties of Cinnamomumzeylanicum (L.) extracts. Biochem.Biophys. Mol. Biol. 2020; 8:1-23.
7. Dorri, M., Hashemitabar S. and Hosseinzadeh, H.: Cinnamon (Cinnamomumzeylanicum) as an antidote or a protective agent against natural or chemical toxicities: A review. Drug Chem. Toxicol. 2018; 41: 338-351.

8. Khasanah U., Prasetyawan P., Utami R., Atmaka W., Manuhara, J. and Sanjaya P.: Optimization and Characterization of Cinnamon Leaves (Cinnamomum burmannii) Oleoresin. IOP Conf. Ser. Mater.Sci. Eng. 2017; 193.

9. Chiang F., Chen Y., Huang C., Lin H. and Hsia M.: Dietary antioxidant trans-cinnamaldehyde reduced visfatininduced breast cancer progression: Invivo and in vitro study. Antioxidants.2019; 8: 625.

10. Abdel-Rahman, A., Harrison L. and Strong N.: Snapshots of scorpion venomics. Journal of Arid Environments, Special issue on Toxins in Desert Environments. 2015; 112: $170-176$.

11. Escalona P., Batista V., Cassulini R., Rios S., Coronas I. and Possani D.:A proteomic analysis of the early secondary molecular effects caused by $\mathrm{Cn} 2$ scorpion toxin on neuroblastoma cells. Journal of Proteomics. 2014; 111: 212-223.

12. Al-Asmari K., Riyasdeen A. and Islam M.: Scorpion venom causes apoptosis by increasing reactive oxygen species and cell cycle arrest in MDA-MB-231 and HCT8 cancer cell lines. Journal of Evidence-Based Integrative Medicine.2018; 23: 215 -225.

13. Wong R.:Apoptosis in cancer: from pathogenesis to treatment. J Exp Clin Cancer Res.2011; 30: 87.

14. Mark A.: The Nuclear Area Factor (NAF):a measure for cell apoptosis using microscopy and image analysis. Mod. Res. Educ. Top. Microsc.2007; 3: 378- 384.

15. Chan YH.: Biostatistics102:Quantitative Data- Parametric \& Non-parametric Tests. Singapore MedJ.2003; 44(8): 391-396.

16. Prasad LK.: Burden of oral cancer: an Indian scenario. $\mathbf{J}$ Orofac Sci. 2014;6(2):77.

17. Liu C., Yang H., Zhang L., Zhang Q., Chen B. and WangY: Biotoxinas para terapia de cancro.Jornal do Pacífico Asiático de Prevençaxode Câncer. 2014.; 1512: 4753-4758.

18. Díaz-García A., Morier-Díaz L. and Frión-Herrera Y.: In vitro anticancer effect of venom from Cuban scorpion Rhopalurusjunceus against a panel of human cancer cell lines. J Venom.2013; 4, 5-12. 
19. Jiang H., Li J, Chen A., Li Y., Xia M., Guo P., Yao S. and Chen S.: Fucosterol exhibits selective antitumor anticancer activity against HeLa human cervical cell line by inducing mitochondrial mediated apoptosis, cell cycle migration inhibition and downregulation of m-TOR/PI3K/Akt signalling pathway. Oncol Lett.2018;15(3): 3458-3463.

20. Valasek M. and Repa J.: The power of real-time PCR. Adv- Physiol Educ. 2005;29(3):151-159.

21. Line V., Malathi N., Thodur B., Durai C. and Dhanapal S.: In Vitro Anticancer Effects of Cinnamomumverum J. Presl, Cinnamaldehyde, Hydroxycinnamic Acid and Eugenol on an Oral Squamous Cell Carcinoma. The Journal of Contemporary Dental Practice.2020; 21:1028-1033.

22. Yufei L., Tian A., Donggui, Bowen Y., Yingyi F. and XiaohuaP.: Targets and Mechanism Used by Cinnamaldehyde, the Main Active Ingredient in Cinnamon, in the Treatment of Breast Cancer. Front. Pharmacol..2020; 11:1-10.

23. Ding J., ChuaJ., Bay B. and Gopalakrishnakone P.: Scorpion venoms as a potential source of novel cancer therapeutic compounds. Experimental biology and medicine. 2014;239:387-393.

24. Zargan J., Sajad M., Umar S., Naime M., Ali S. and Khan H.: Scorpion (Androctonus crassicauda) venom limits growth of transformed cells (SH- SY5Y and MCF-7) by cytotoxicity and cell cycle arrest. Experimental and Molecular Pathology.2011; 91: 447-454.

25. Nazhvani A., Sarafraz N., Askari F., Heidari F. and Razmkhah M.:Anti-cancer effects of traditional medicinal herbs on oral squamous cell carcinoma. Asian Pacific journal of cancer prevention: 2020;21(2):479.
26. Herdwiani W.: A review of cinnamon as a potent anticancer. Asian J Pharm Clin Res.2016; 5: 8-13.

27. Kwon K., Hwang S. and So S.: Cinnamon extract induces tumor cell death through inhibition of NF kappa B and AP1. BMC Cancer.2010; 10: 1471-2407.

28. Kianpour Rad S, Kanthimathi MS, Abd Malek SN, Lee GS, Looi CY and Wong WF. Cinnamomum cassia suppresses caspase-9 through stimulation of AKT1 in MCF-7 cells but not in MDA-MB-231 cells. PloS one. 2015;10(12):e0145216.

29. Panja K, Buranapraditkun S, Roytrakul S, Kovitvadhi A, Lertwatcharasarakul P, Nakagawa T, Limmanont C and Jaroensong T:. Scorpion Venom Peptide Effects on Inhibiting Proliferation and Inducing Apoptosis in Canine Mammary Gland Tumor Cell Lines. Animals. 2021;11(7):2119.

30. Li J, Teng Y, Liu S, Wang Z, Chen Y, Zhang Y, Xi S, Xu S, Wang R and Zou X:. Cinnamaldehyde affects the biological behavior of human colorectal cancer cells and induces apoptosis via inhibition of the PI3K/Akt signaling pathway. Oncology reports. 2016; 35(3):1501-10.

31. Satitmanwiwat, S., Changsangfa, C.,Khanuengthong, A., Promthep K., Roytrakul S., Arpornsuwan T.,Saikhun K. and Sritanaudomchai H.: The scorpion venom peptide BmKn2 induces apoptosis in cancerous but not in normal human oral cells. Biomed.Pharmacother.2016; 84: 1042-1050.

32. Díaz-García A, Ruiz-Fuentes JL, Rodríguez-Sánchez H and Castro JA.: Rhopalurus junceus scorpion venom induces apoptosis in the triple negative human breast cancer cell line MDA-MB-231. Journal of venom research. 2017;8:9-13. 